\title{
Unrewarded trials and resistance to extinction of a bar-pressing response ${ }^{1}$
}

\author{
J. DUTCH ${ }^{2}$ AND DAVID QUARTERMAIN ${ }^{3}$ \\ UNIVERSITY OF AUCKLAND
}

Two experiments in a free-operant situation tested the generality of Lawrence \& Festinger's (1962) hypothesis that the total number of nonreinforced trials, not percentage of reward, is the critical variable in determining resistance to extinction. This was supported by Experiment 1. However, when rate of responding was held constant in Experiment 2 the hypothesis was not supported. The results suggest that $S$ 's with faster rates of responding in acquisition make more responses in extinction indicating an energizing effect of nonreinforcement.

Lawrence \& Festinger (1962) have hypothesized that the partial reinforcement effect (PRE) may be understood in terms of a theory of cognitive dissonance. According to the hypothesis, dissonance occurs on each unrewarded trial but $S$ learns to reduce this dissonance by finding "extra attractions" in the situation and so continues to perform the response in the absence of the normal reward. A corollary of this hypothesis is that it is the total number of unrewarded trials that determines resistance to extinction, and not, as commonly assumed, percentage of reward. In support of this Lawrence and Festinger report an experiment in which three levels of unrewarded trials and three percentages of reward were combined in $a$ by 3 factorial design. The apparatus was an $\mathrm{S}$-shaped runway containing obstructions. Results showed that the only significant effect was number of unrewarded trials. Since recent theorizing on the PRE suggests that discrete trial and free responding situations may not yield comparable data (Amsel, Rashotte, \& MacKinnon, 1966), it would seem profitable to test the generality of Lawrence and Festinger's finding by attempting to replicate the results in a standard free operant situation.

\section{EXPERIMENT 1}

\section{Subjects}

Ss were 44 experimentally naive male albino rats of the Wistar strain with ages ranging from 155 to 175 days at the commencement of the experiment. Precedure

Apparatus consisted of three Skinner boxes each equipped with a bar requiring a force of $15 \mathrm{~g}$ to depress. The reinforcing mechanism was a modified Deutsch Spaghetti Gun (Trotter, 1956) which dispensed pieces of commercial spaghetti with a mean weight of $20 \mathrm{mg}$.

Three weeks before the beginning of the experiment Ss were deprived of food for $48 \mathrm{~h}$ and thereafter maintained on a diet of $8 \mathrm{~g}$ of lab chow per day. Water was ad lib. During this time Ss were tamed and magazine trained. The experimental design was a 2 by 2 factorial using randomized blocks with two values of nonrewarded (NR) trials, 400 and 800 , and two percentages of reward, $66-2 / 3$ and 20 . Ss were assigned to groups on the basis of operant level responding.

On the first two days of acquisition Ss were removed from the apparatus after making 100 responses. Thereafter each $\mathrm{S}$ was run for $\mathbf{3 0}$ min daily untll the required total of responses was made.

Extinction was commenced 23 h after each $S$ had completed acquisition. After being placed in the box each $S$ remained there until it had reached a criterion of $10 \mathrm{~min}$ of nonresponding. Conditions during extinction were the same as those during acquisition. This was achieved by running a blank flim through the programmer.

\section{Results and Discussion}

An analysis of variance of the extinction scores indicated that the only significant effect was the number of NR trials $(F=11.39, d f=1 / 30, p<.01)$. This result supports the Lawrence and Festinger hypothesis. However, an examination of the data suggests some qualification of the main finding; in particular, the following points require consideration. (1) From a study of the acquisition curves it was apparent that no group had reached asymptote in acquisition. (2) A significant correlation between the last $10 \mathrm{~min}$ of acquisition and the total extinction score $(r=.50 ; t$ $=4.32, \mathrm{df}=42, \mathrm{p}<.001$ ) shows that terminal acquisition rate is significantly related to number of responses in extinction. (3) The two groups which received 800 NR trials had significantly higher terminal acquisition response rates than the other two groups, which received $400 \mathrm{NR}$ trials $(F=18.44, \mathrm{df}=1 / 30, p<.001)$.

These data suggest that one of the major effects of unrewarded trials in PRE is to increase response rate. Since the response rate in acquisition is positively correlated with the number of responses emitted in extinction it would be expected that groups receiving more unrewarded trials in acquisition would make more responses in extinction. This suggests that if acquisition were continued until response rates stabilized, increasing the number of unrewarded trials past this point would not result in increased resistance to extinction. A second experiment was designed to test this hypothesis. 


\section{EXPERIMENT 2}

Subjects

Ss were 22 experimentally naive male albino rats of the Wistar strain with ages ranging from 155 to 175 days at the commencement of the experiment. Procedure

Apparatus was the same as for Experiment 1. All Ss were trained on an FR 20 reinforcement schedule and were given acquisition until response rate had levelled off and remained stable over a period of 3000 trials. At this point Ss were divided into two groups with equivalent rates of responding of the 7 th, 8 th, and 9th thousand responses, using a randomized blocks procedure. One group $(\mathrm{N}=11)$ which had received a total of 7200 unreinforced trials was then extinguished. The second group $(\mathrm{N}=11)$ was continued for a further 9000 responses giving a total of 14,400 unreinforced trials, twice the number of the first group. The second group was then extinguished. Criterion for extinction was the same as in Experiment 1. Results and Discussion

Analysis of variance indicates that the number of responses emitted in extinction by the two groups was not significantly different $(F=0.19, d f=1 / 10)$, indicating that resistance to extinction is not increased by additional unrewarded trials after response rates have reached asymptote. The significance of response rate in acquisition for resistance to extinction was again demonstrated by a positive correlation between rate in the last $10 \mathrm{~min}$ of acquisition and total number of responses in extinction $(r=0.48 ; t=2.45, d f=20$, $\mathrm{p}<.05$ ).

Although the results of the present experiments support Lawrence and Festinger's hypothesis that the number of unrewarded trials rather than the ratio of reward is the major determinant of resistance to extinction of a partial reinforcement schedule, they also suggest a simpler interpretation. Our results would seem to indicate that increasing the number of unrewarded trials simply increases rate of bar pressing in acquisition, and Ss with faster rates of responding make more responses in extinction. While the nature of this relation between rate in acquisition and resistance to extinction cannot be determined from the present experiments, our results indicate an energizing effect of nonreinforcement as described by Amsel (1962).

\section{References}

AMSEL, A. Frustrative nonreward in partial reinforcement and discrimination learning. Psychol. Rev., 1962, 69, 306-328.

AMSEL, A., RASHOTTE, M. E., \& MacKINNON, J. R. Partial reinforcement effects within subject and between subjects. Psychol. Monogr., 1966, 80 (20, Whole No. 628).

LAWRENCE, D. H., \& FESTINGER, L. Deterrents and reinforcement. Stanford University Press, 1962.

TROTTER, J. R. The physical properties of bar pressing behaviour and the problem of reactive inhibition. Quart. J. exp. Psychol., $1956,8,97-106$.

Notes

1. Based on an MA thesis by J. Dutch.

2. Now at Massey University, New Zealand.

3. Now at Rockefeller University, New York. 